\title{
A Comparison of the Fine-scale Structure of the Diurnal Cycle of Tropical Rain and Lightning
}

\author{
V. Venugopal ${ }^{\mathrm{a}, \mathrm{b}, *}$, K. Virts ${ }^{\mathrm{c}}$, J. Sukhatme ${ }^{\mathrm{a}, \mathrm{b}}$, J. M. Wallace ${ }^{\mathrm{c}}$, B. Chattopadhyay ${ }^{\mathrm{a}, \mathrm{d}}$ \\ ${ }^{a}$ Centre for Atmospheric and Oceanic Sciences, Indian Institute of Science, Bangalore, India \\ ${ }^{b}$ Divecha Centre for Climate Change, Indian Institute of Science, Bangalore, India \\ ${ }^{c}$ Department of Atmospheric Sciences, University of Washington, Seattle, WA, USA. \\ ${ }^{d}$ Swiss Re Private Limited, Bangalore, India
}

\begin{abstract}
In this study, the fine-scale structure of the diurnal variability of ground-based lightning is systematically compared with satellite-based rain. At the outset, it is shown that tropical variability of lightning exhibits a prominent diurnal mode, much like rain. A comparison of the geographical distribution of the timing of the diurnal maximum shows that there is very good agreement between the two observables over continental and coastal regions throughout the tropics. Following this global tropical comparison, we focus on two regions, Borneo and equatorial South America, both of which show an interplay between oceanward and landward propagation of the phase of the diurnal maximum. Over Borneo, both rain and lightning clearly show a climatological cycle of "breathing in" (afternoon to early morning) and "breathing out" (morning to early afternoon). Over the equatorial east coast of South America, landward propagation is noticed in rain and lightning from early afternoon to early morning. Along the Pacific coast of South America, both rain and lightning show oceanward propagation. Though qualitatively consistent, over both regions the propagation is seen to extend further in rainfall. Additionally, given that lightning highlights vigorous convection, the timing of its diurnal maximum often precedes that of rainfall in the convective life cycle.
\end{abstract}

Keywords:

Tropical Rain, Lightning, Diurnal Cycle, Propagation

\section{Introduction}

Tropical climate exhibits variability over a range of space and time scales. From a temporal viewpoint, a rough catalog consists of interannual phenomena (such as El Niño / Southern Oscillation), seasonal cycles, intraseasonal modes (such as the Madden Julian Oscillation), synoptic

*Corresponding Author: venu@caos.iisc.ernet.in 
systems (such as convectively coupled equatorial waves) and the diurnal cycle. Much of this variability (and its geographic distribution) manifests itself in moist variables, such as rain, with the diurnal cycle being one of the more dominant modes.

Early work on diurnal variability of rainfall was limited to regional analysis using groundbased observations (Wallace, 1975; Kousky, 1980; Pathan, 1994); these studies showed that over continental regions, there is a strong preference for late afternoon/early evening rain. Studies based on proxies (Hendon and Woodberry, 1993; Chen and Houze, 1997) suggested that rainfall over the ocean typically tends to occur in the early morning hours; however, some studies (Gray and Jacobson, 1977; McGarry and Reed, 1978; Shin et al., 1990) reported an afternoon maximum in oceanic rain, at least in some regions. One of the earliest global studies of the diurnal cycle, based on station observations, was by Dai (2001). Using 3-hourly weather reports, he found that drizzle tends to occur around the early morning hours over land, versus around midnight over oceans. On the other hand, showery precipitation and thunderstorms tend to occur in the late afternoon hours over land regions.

More recent studies have explored the diurnal cycle using satellite rainfall data (Zuidema, 2003; Barros et al., 2004; Nesbitt and Zipser, 2003; Liu et al., 2007; Hirose et al., 2008; Yang and Smith, 2008; Kikuchi and Wang, 2008; Biasutti et al., 2012; Prat and Nelson, 2014). In addition to verifying results from station data and proxies, a common finding was that the diurnal cycle over land is stronger than over ocean, and is stronger in summer than during winter. Another prominent feature of the diurnal cycle in rainfall is its phase propagation in coastal regions, e.g., along the western coast of central Africa (McGarry and Reed, 1978; Liang et al., 2008), the Bay of Bengal (Yang and Slingo, 2001; Gambheer and Bhat, 2001; Zuidema, 2003), the coast of Sumatra (Mori et al., 2004) and the northwestern coast of South America (Mapes et al., 2003a,b).

The recent availability of global lightning datasets, especially at very fine space and time scales, provides us an avenue to analyze the occurrence of the most intense convection and compare its variability with that of precipitation. Seasonal variations in global lightning occurrence have been documented by Christian et al. (2003) and Blakeslee et al. (2014), based on data from the Optical Transient Detector (OTD). Analysis of tropical- and regional-mean diurnal lightning from the Lightning Imaging Sensor (LIS; Christian et al., 1999) has indicated an evening peak in lightning over land areas and an early morning peak over oceanic areas (e.g., see Liu and Zipser, 2008; Sen Roy and Balling, 2013). However, the infrequent sampling from the satellite-borne OTD and LIS has mostly limited the analysis of the geographic distribution of diurnal lightning variability. Virts et al. (2013a) demonstrated the ability of ground-based lightning networks to capture known features of the diurnal variability of convection near coastlines and topography in select tropical regions.

No comprehensive documentation of diurnal regimes of lightning, or comparison with those of rainfall, has been attempted to date. In this short note, we systematically document the finescale structure of tropical diurnal variability of lightning, and compare it with that of rainfall. Specifically, we begin with a global perspective, i.e., establish the dominance of the diurnal mode of lightning variability, and make a comparison of the geographical distribution of its phase with that of rainfall. As a more stringent test of the ability of lightning to capture convection, we then focus on two regions, the island of Borneo and the equatorial Pacific and Atlantic South American 
coasts, where the coastal propagation is unconventional.

\section{Data and Methods}

Our study uses 15 years (1998-2012) of Tropical Rainfall Measurement Mission (TRMM 3B42) data covering the global tropics (30S-30N), and 4 years (2008-2011) of lightning data from the World Wide Lightning Location Network (WWLLN). A detailed description of the rainfall data can be found at http://trmm.gsfc.nasa.gov/3b42.html (see also Simpson et al., 1996; Huffman et al., 2007). The rainfall product has a temporal and spatial resolution of 3 hours, and $0.25^{\circ} \times 0.25^{\circ}$, respectively. Several validation studies of TRMM 3B 42 rainfall data have been performed with ground-based observations and the rainfall estimates are generally considered reliable (Nicholson et al., 2003; Rahman et al., 2009; Shin et al., 2011; Mantas et al., 2015). It is worth noting here that we analyse the new and improved TRMM 3B42 product (V7) (e.g., see Liu, 2015), while many previous studies on the fine-scale structure of precipitation have used V6 data.

Documentation of the ground-based lightning data used in this study can be found at http: / / wwlln. net (Dowden et al., 2002). The WWLLN network consisted of $\approx 70$ stations at the end of 2011 (station locations are shown in Fig. 1 of Virts et al. 2013b) and locates lightning to within $\approx 5 \mathrm{~km}$ and $<10$ microseconds (Abarca et al., 2010). Its global detection efficiency of $\approx 10 \%$ (Rodger et al., 2009; Abarca et al., 2010; Hutchins et al., 2012; Rudlosky and Shea, 2013) enables it to detect nearly all lightning-producing storms (Jacobson et al., 2006). WWLLN detects proportionately more lightning over ocean and less over land compared to optical lightning sensors (Rudlosky and Shea, 2013; Hutchins et al., 2013). For the purposes of this study, WWLLN lightning observations were assigned to a spatial grid matching that of the TRMM 3B42 dataset. Hourly maps of lightning frequency were generated based on the number of flashes observed in each grid box, which are then cumulated in time to obtain a 3-hourly lightning dataset.

We follow different approaches to estimate the time of day when maximum rainfall/lightning is observed. For the TRMM 3-hourly data, for which a longer period of record (1998-2012) is available, we estimate the time of day when maximum rainfall is observed, using harmonic analysis. Specifically, we first compute the Fourier transform of the 3-hourly rainfall at each grid point for every year. (The number of samples per grid point per year is $365 \times 8=2920$.) Following this, a time series of rainfall anomalies is constructed by removing (zeroing) all Fourier coefficients corresponding to time-scales greater than 1 day. This filtering procedure is mainly aimed at isolating diurnal characteristics (equivalently, removing the influence of longer timescales). In other words, the reconstructed time series, referred to from here on as the diurnal anomaly, only contains diurnal (and subdiurnal) variations. From this diurnal anomalies time series, we identify that 3-hour period (peak octet) in which the anomaly is a positive maximum for each day for 15 years. The mode of the frequency distribution of the peak octet is estimated and used to characterise the time of maximum rainfall. For more details on the filtering as well as the possible pitfalls in using the climatology of 3-hourly rainfall for identifying the time of maximum rainfall, we refer to Sahany et al. (2010). For the WWLLN 3-hourly data, we construct the diurnal anomalies by removing the daily mean climatology (2008-2012). Finally, the phase of the diurnal maximum is the 3-hour period with the highest number of lightning strokes. 


\section{Results}

\subsection{Global Tropical Features: Rain vs. Lightning}

A defining feature of rainfall is that regions with high mean also exhibit large variability (for instance, monsoon hotspots and intertropical convergence zones; see Gershunov and Michaelsen, 1996; Chattopadhyay, 2012). This is also true of lightning (figure not shown). In order to assess the distribution of variability across different timescales, we estimate a point-wise power spectrum; specifically, the spectra of lightning strokes and rainfall at each grid point are computed and then climatological spatial averages constructed (Fig. 1). Besides the considerably "reddish" character of rain compared to lightning, it is quite clear from the spectra that seasonal and diurnal cycles are the most dominant timescales in both the observables. Note that this method of estimating the spectrum is a local point of view and, by construction, suppresses longer timescale variability, as seen by the relatively flat nature of the spectrum between 2 and 100 days. ${ }^{1}$

Having established the dominance of the diurnal cycle of rainfall and lightning, we now focus on the diurnal phase (3-hour period) of maximum rainfall/lightning. Fig. 2 shows the climatology of this phase for rainfall (left column) and lightning (right column). The well-documented preference for an evening maximum over continental land is clearly evident from the figure, as is the more complex behaviour near mountain ranges such as the Himalayas and Andes. In addition, in coastal regions, an oceanward propagation of the phase of the diurnal maximum, as noted by several previous studies, is observed. Examples include the Bay of Bengal and Sumatra (Fig. 2c,d) and off the northwestern (Pacific) coast of South America (Fig. 2e,f). Oceanic regions with frequent deep convection (e.g., the tropical convergence zones) often do not experience much lightning (Zipser, 1994; Virts et al., 2013b); this could partly explain the noisy appearance and lack of coherent structure seen over the oceans. Given this broad agreement, we proceed to an examination of the Island of Borneo (Fig. 2c,d) and the equatorial coast of South America (Fig. 2e,f), which show an interplay of oceanward and landward propagation. It is worth noting here that since both these regions are very close to the Equator, the seasonal cycle is not very strong; in fact, we have verified that the contributions of the seasonal diurnal variance during Boreal winter and summer are of the same order of magnitude. Hence, the discussion that follows pertains to the entire year.

\subsection{Coastal Propagation}

Island of Borneo: A comparison of the phase of the diurnal maximum between lightning and rain is shown in Fig. 3. Clearly, the differences in timing over most of the island, especially near the coasts, are within the temporal resolution afforded by the TRMM data (i.e., \pm 3 hours). However, it is worth noting that where differences in timing exist, more often than not, lightning precedes precipitation (i.e., negative values in Fig. 3). This is consistent with the tendency for lightning to occur earlier in the convective life cycle (Houze, 2014).

\footnotetext{
${ }^{1}$ A comparison of the ratio of the variance of diurnal anomalies (time scales $\leq 1$ day) to the total annual variance of rain (e.g., Ruane and Roads, 2007) and lightning shows a better match over continental regions than over open oceans.
} 
The spatial structure of the phase of the diurnal maximum over the island of Borneo (Fig. 2c,d) shows multiple times of day of maximum rainfall, suggesting propagation. To establish the direction of propagation, Fig. 4 (left column) shows the 3-hourly diurnal rainfall anomalies over the Indonesian islands. From these anomalies a clearer picture emerges: rainfall begins along the outer boundaries of Borneo around 15LT in association with the afternoon sea breeze, intensifies during the early evening (18LT), and progresses inwards (21LT $\rightarrow 00 \mathrm{LT})$. By midnight, the rain is localized in the centre of the island, near the higher topography. Around early morning (06LT), the intensity of the island rain has decreased, and the rainfall anomalies that began over the coastal regions around 03LT have intensified. This anomaly propagates outwards over the ocean from 06LT to $12 / 15 \mathrm{LT}$, by which time a strong negative anomaly develops over the island. In essence, the cycle that emerges is akin to "breathing in" $(15 \mathrm{LT} \rightarrow 18 \mathrm{LT} \rightarrow 21 \mathrm{LT} \rightarrow 00 \mathrm{LT} \rightarrow 03 \mathrm{LT})$ and "breathing out" (06LT $\rightarrow$ 09LT $\rightarrow 12 \mathrm{LT} \rightarrow 15 \mathrm{LT})$. The propagation speed estimated from these climatological anomalies is approximately $5-10 \mathrm{~m} / \mathrm{s}$, which is consistent with the TRMM Precipitation Radar-based findings of Ichikawa and Yasunari (2006).

The behavior of lightning (right column of Fig. 4) is in agreement with that of rain, although minor differences in the timing are noticed, with lightning generally preceding rainfall (Fig. 3). In fact, the breathing in and out is even more striking in WWLLN data, possibly because of its higher temporal sampling. Previous studies have also noted the strong diurnal cycle in convection over Borneo and the offshore initiation and propagation of convective anomalies during the night (Houze et al., 1981; Wu et al., 2008; Teo et al., 2011; Qian et al., 2013; Virts et al., 2013b). Similar behaviour is observed in the rain and lightning anomalies over Papua New Guinea, although the offshore propagation of lightning is much less pronounced than that of rain.

It is to be noted that the "breathing in/breathing out" phenomenon described above is a climatological composite. In particular, the breathing in or breathing out can be a preferred mode, depending on the dynamical regime, i.e., the prevailing winds. For instance, it has been noted that the low-level winds have a prominent intraseasonal easterly/westerly component (see Fig. 6/Table 1 in Ichikawa and Yasunari, 2006) that would favor oceanward ("breathing out") on some days and landward ("breathing in") propagation on others. The diurnal cycle of lightning is modulated by the direction of the prevailing winds, with both oceanward and landward propagation enhanced on the leeward side of the mountains (Virts et al., 2013a).

The early-to-late evening preference for rain over Borneo is consistent with the classical continental maximum. The transport of moist air from ocean to land, associated with thermally-driven sea breezes, coupled with the gradual increase in elevation, is responsible for the observed "breathing in" of rain anomalies (Ichikawa and Yasunari, 2006; Hara et al., 2006). With regard to the "breathing out", the presence of positive anomalies far away from the coast (at 12,15LT) implies a substantial extent of seaward propagation. In addition to the thermally driven nocturnal downslope and offshore airflow, the destabilising effect of gravity waves (Mapes et al., 2003b) could be responsible for this relatively remote response.

South America: Fig. 5 shows the difference in the phase of the diurnal maximum over South America; Overall, as in the case of Borneo, the differences in timing lie within the temporal resolution afforded by the data ( \pm 3 hours), with an exceptionally good agreement in the interior regions. In addition, lightning leads rainfall in a coherent band along the eastern coast. This is consistent 
with the fact that precipitation tends to persist after vigorous convection has weakened. Differences in timing between precipitation and lightning are also observed over the eastern foothills of the Andes. The complex topography of the foothills, and the resulting valley and mountain breeze circulations (Virts et al., 2013a), contribute to the local differences in diurnal timing. In Fig. 2e, we see a rich structure in the time of maximum rain along the equatorial coast of South America. In particular, while its Pacific coast shows a conventional oceanward propagation, the eastern coast shows landward propagation. Once again, to examine these features in detail, Fig. 6 (left column) shows the reconstructed 3-hourly diurnal rainfall anomalies. Along the east coast, strong positive anomalies emerge around $15 \mathrm{LT}$, and systematically propagate landward and inward from early evening (18LT) to early morning (03LT - 06LT), with a speed of approximately $10 \mathrm{~m} / \mathrm{s}$. The landward propagation is broadly consistent with previous studies of the diurnal cycle of convection over Amazonia, which have noted that the sea breeze-induced convection along the coast sometimes develops into squall lines that subsequently propagate inland (Garstang et al., 1994; Cohen et al., 1995; Sorooshian et al., 2002; Brito and Oyama, 2014). Around the same time (15LT), two parallel, coherent bands of positive rain anomalies form over Amazonia (similar features were observed in cloudiness data by Garreaud and Wallace, 1997), which strengthen by 18LT and contribute to the well-established evening maximum over land. Positive anomalies appear along the Pacific coast around 18LT and strengthen through 21LT; these anomalies persist through the early morning hours (00LT, 03LT), and then propagate out into the ocean (06LT to 18LT). This oceanward propagation along the west coast, with a phase speed of approximately $15-20 \mathrm{~m} / \mathrm{s}$, is consistent with previous findings based on the GOES Precipitation Index (Mapes et al., 2003a,b).

In the 3-hour lightning climatology in Fig. 6 (right column), the evening maximum over land is the most striking feature (see also recent work by Ávila et al., 2015). In addition, we also see a hint of the parallel bands of positive anomalies over Amazon at 15LT; however, this signal is not as prominent as in rainfall. Lightning is enhanced along the northeastern coast during afternoon and early evening (15LT $\rightarrow 18 \mathrm{LT})$. The diurnal phase map in Fig. $2 \mathrm{f}$ indicates that the lightning maximum propagates inland along with rain (Fig. 2e), but the magnitude of the nocturnal lightning over the Amazon is small (Fig. 6). The observed differences in inland extent of the landward propagation from the Atlantic coast indicate that precipitation lingers after the lightning has weakened. Over northwestern South America, lightning is enhanced near the mountain slopes during evening (18LT and 21LT) and weakens after midnight. Positive anomalies of lightning emerge over the coast around $03 \mathrm{LT}$ and move oceanward during morning $(06 \mathrm{LT} \rightarrow 12 \mathrm{LT})$. Rainfall anomalies over the Panama basin persist longer and extend farther offshore than the lightning, indicating a weakening of the convection as it moves away from the coast (compare with Fig. 5). A cursory examination of the low-level winds (figure not shown) from reanalysis data shows that they are predominantly easterly (with a mean speed of $8-10 \mathrm{~m} / \mathrm{s}$ ) through the year along the equatorial east coast of South America (see also Mapes et al., 2003a). Thus, in contrast to the situation over Borneo, this suggests that the propagation described above occurs through the year.

\section{Summary}

In this work, we compare and contrast the fine-scale structure of the diurnal cycle of groundbased lightning with remotely sensed rainfall over the tropics. Overall, we see that the lightning 
captures most of the well established features of the diurnal cycle of rainfall. In particular, the most prominent mode in tropical lightning variability is at the diurnal scale. Moreover, the timing of the respective diurnal maxima are in good agreement (at least within the resolution afforded by the observations), especially over the continental and coastal regions where the diurnal cycle is known to be strong. It is worth noting that over the open oceans, the match between lightning and rainfall is not as good; this could be either due to the relative weakness of the diurnal cycle itself or the scarcity of lightning over most open oceanic areas. As a whole, our analysis shows that there is remarkable agreement between the amplitude and phase of the diurnal cycles of lightning and rain throughout the tropics. Thus, though spatially sparse, the lightning network observations can be seen as a potentially new avenue to explore the fine-scale temporal structure of rainfall.

As a further comparison of the diurnal variability of precipitation and lightning, we focus on two coastal regions, namely, the coasts of Borneo and equatorial South America, both of which show an interplay of oceanward and landward propagation of the phase of the diurnal cycle. Climatologically, both rain and lightning show a cycle characterized by "breathing in" and "breathing out" over Borneo. In the context of South America, while landward propagation is noticed in rain over the east coast, it is not as prominent in lightning. Along the equatorial Pacific coast, both rain and lightning show an oceanward propagation, with a larger spatial extent in rainfall, as in the case of Borneo. In both case studies, where propagation of the diurnal phase is observed, lightning tends to lead rainfall, consistent with vigorous updrafts and lightning production in the developing stage of deep convection, and rain production continuing during the mature and dissipating stages (Futyan and Del Genio, 2007a,b). 


\section{Acknowledgments}

VV and JS acknowledge support of the Space Technology Cell ISTC/MAS/VV/320ISTC and ISTC/MAE/JSS/0352) and the Divecha Centre for Climate Change at the Indian Institute of Science. KV was supported by the National Aeronautics and Space Administration (grant \#NNX10AM28G) and the U.S. Department of Energy (grant \#DE-SC008452). We thank the TRMM science data and information system (TSDIS) and the Goddard distributed active archive center for providing us the TRMM data. Lightning location data were provided by WWLLN (http://wwlln. net), a collaboration among over 50 universities and institutions. 


\section{References}

Abarca, S. F., Corbosiero, K. L., Galarneau, T. J., 2010. An evaluation of the Worldwide Lightning Location Network (WWLLN) using the National Lightning Detection Network (NLDN) as ground truth. Journal of Geophysical Research 115, D18206, DOI:10.1029/2009JD013411.

Ávila, E. E., Bürgesser, R. E., Castellano, N. E., Nicora, M. G., 2015. Diurnal patterns in lightning activity over South America. Journal of Geophysical Research: Atmospheres, 3103-3113.

Barros, A. P., Kim, G., Williams, E., Nesbitt, S., 2004. Probing orographic controls in the Himalayas during the monsoon using satellite imagery. Natural Hazards and Earth Systems Science 4, 29-51.

Biasutti, M., Yuter, S. E., Burleyson, C. D., Sobel, A. H., 2012. Very high resolution rainfall patterns measured by TRMM precipitation radar: Seasonal and diurnal cycles. Climate Dynamics, DOI:10.1007/s00382-011-1146-6.

Blakeslee, R. J., Mach, D. M., Bateman, M. G., Bailey, J. C., 2014. Seasonal variations in the lightning diurnal cycle and implications for the global electric circuit. Atmospheric Research $135-136,228-243$.

Brito, S., Oyama, M., 2014. Daily cycle of precipitation over the northern coast of Brazil. Journal of Applied Meteorology and Climatology, DOI:10.1175/JAMC-D-14-0029.1.

Chattopadhyay, B., 2012. Fine-scale structure of the diurnal cycle of global tropical rainfall. Master's thesis, Indian Institute of Science, Bangalore.

Chen, S. S., Houze, Jr., R. A., 1997. Diurnal variation and life-cycle of deep convective systems over the tropical Pacific warm pool. Quarterly Journal of the Royal Meteorological Society 123 (538), 357-388.

Christian, H. J., Blakeslee, R. J., Boccippio, D. J., coauthors, 2003. Global frequency and distribution of lightning as observed from space by the Optical Transient Detector. Journal of Geophysical Research, DOI:10.1029/2002JD002347.

Christian, H. J., Blakeslee, R. J., Goodman, S. J., coauthors, 1999. The Lightning Imaging Sensor. Proc. 11th Int. Conf. on Atmospheric Electricity, 726-729.

Cohen, J. C. P., Silva Dias, M. A. F., Nobre, C. A., 1995. Environmental conditions associated with amazonian squall lines: A case study. Monthly Weather Review 123, 3163-3174.

Dai, A., 2001. Global precipitation and thunderstorm frequencies. Part II: Diurnal variations. Journal of Climate 14 (6), 1112-1128.

Dowden, R. L., Brundell, J. B., Rodger, C. J., 2002. VLF lightning location by time of group arrival (TOGA) at multiple sites. Journal of Atmospheric and Solar-Terrestrial Physics 64, 817-830.

Futyan, J. M., Del Genio, A. D., 2007a. Relationships between lightning and properties of convective cloud clusters. Geophysical Research Letters 34, L15705. 
Futyan, J. M., Del Genio, A. D., 2007b. Deep convective system evolution over Africa and the tropical Atlantic. Journal of Climate 20, 5041-5060.

Gambheer, A. V., Bhat, G. S., 2001. Diurnal variation of deep cloud systems over the Indian region using INSAT-1B pixel data. Meteorology and Atmospheric Physics 78 (3), 215-225.

Garreaud, R. D., Wallace, J. M., 1997. The diurnal march of convective cloudiness over the Americas. Monthly Weather Review 125, 3157-3171.

Garstang, M., Massie Jr., H. L., Halverson, J., Greco, S., Scala, J., 1994. Amazon coastal squall lines. Part I: Structure and kinematics. Monthly Weather Review 122, 608-622.

Gershunov, A., Michaelsen, J., 1996. Climatic-scale space-time variability of tropical precipitation. Journal of Geophysical Research 101, 26,927-26,307.

Gray, W. M., Jacobson, R. W., 1977. Diurnal variation of deep cumulus convection. Monthly Weather Review 105 (9), 1171-1188.

Hara, M., Yoshikane, T., Kimura, F., 2006. Mechanism of diurnal cycle of convective activity over Borneo Island. Proceedings of the 7th WRF Users' Workshop, NCAR, Boulder, US.

Hendon, H. H., Woodberry, K., 1993. The diurnal cycle of tropical convection. Journal of Geophysical Research 98 (D9), 623-637.

Hirose, M., Oki, R., Shimizu, S., Kachi, M., Higashiuwatoko, T., 2008. Finescale diurnal rainfall statistics refined from eight years of TRMM PR data. Journal of Applied Meteorology and Climatology 47, 544-561.

Houze, Jr., R. A., 2014. Cloud Dynamics, 2nd Edition. Elsevier.

Houze, Jr., R. A., Geotis, S. G., Marks Jr., F. D., West, A., 1981. Winter monsoon convection in the vicinity of north Borneo. Part I: Structure and time variation of the clouds and precipitation. Monthly Weather Review 109, 1595-1614.

Huffman, G. J., Adler, R. F., Bolvin, D. T., Gu, G., Nelkin, E. J., Bowman, K. P., Hong, Y., Stocker, E. F., Wolff, D. B., 2007. The TRMM multi-satellite precipitation analysis: Quasi-global, multiyear, combined-sensor precipitation estimates at fine scale. Journal of Hydrometeorology 8 (1), $38-55$.

Hutchins, M. L., Holzworth, R. H., Brundell, J. B., Rodger, C. J., 2012. Relative detection efficiency of the World Wide Lightning Location Network. Radio Science 47, DOI:10.1029/2012RS005049.

Hutchins, M. L., Holzworth, R. H., Virts, K. S., Wallace, J. M., Heckman, S., 2013. Radiated VLF energy differences of land and oceanic lightning. Geophysical Research Letters 40, 1-5.

Ichikawa, H., Yasunari, T., 2006. Time-space characteristics of diurnal rainfall over Borneo and surrounding oceans as observed by TRMM-PR. Journal of Climate 19, 1238-1260. 
Jacobson, A. R., Holzworth, R., Harlin, J., Dowden, R., Lay, E., 2006. Performance assessment of the World Wide Lightning Location Network (WWLLN), using the Los Alamos Sferic Array (LASA) as ground truth. Journal of Atmospheric and Oceanic Technology 23, 1082-1092.

Kikuchi, K., Wang, B., 2008. Diurnal precipitation regimes in the global tropics. Journal of Climate 21 (11), 2680-2696.

Kousky, V. E., 1980. Diurnal rainfall variation in northeast Brazil. Monthly Weather Review 108, 488-498.

Liang, A. G., Carbone, R., Levizzani, V., Tuttle, J., 2008. The propagation and diurnal cycles of deep convection in Northern tropical Africa. Quarterly Journal of the Royal Meteorological Society 138, 93-109.

Liu, C., Zipser, E. J., 2008. Diurnal cycles of precipitation, clouds, and lightning in the tropics from 9 years of TRMM observations. Geophysical Research Letters 35, L04819.

Liu, C., Zipser, E. J., Nesbitt, S. W., 2007. Global distribution of tropical deep convection: Different perspectives from TRMM infrared and radar data. Journal of Climate 20 (3), 489-503.

Liu, Z., 2015. Comparison of precipitation estimates between Version 7 3-hourly TRMM MultiSatellite Precipitation Analysis (TMPA) near-real-time and research products . Atmospheric Research 153, 119-133.

Mantas, V. M., Liu, Z., Caro, C., Pereira, A. J. S. C., 2015. Validation of TRMM multi-satellite precipitation analysis (TMPA) products in the Peruvian Andes. Atmospheric Research, In Press, DOI:10.1016/j.atmosres.2014.11.012.

Mapes, B. E., Warner, T. T., Xu, M., 2003a. Diurnal patterns of rainfall in northwestern South America. Part I: Observations and context. Monthly Weather Review 131, 799-812.

Mapes, B. E., Warner, T. T., Xu, M., 2003b. Diurnal patterns of rainfall in northwestern South America. Part III: Diurnal gravity waves and nocturnal convection offshore. Monthly Weather Review 131, 830-844.

McGarry, M. M., Reed, R. J., 1978. Diurnal variations in convective activity and precipitation during phases II and III of GATE. Monthly Weather Review 106, 101-113.

Mori, S., Hamada, J. I., Tauhid, Y. I., Yamanaka, M. D., Okamoto, N., Murata, F., Sakurai, N., Hashiguchi, H., , Sribimawati, T., 2004. Diurnal land-sea rainfall peak migration over Sumatra Island, Indonesian maritime continent, observed by TRMM satellite and intensive rawinsonde soundings. Monthly Weather Review 132, 2021-2039.

Nesbitt, S. W., Zipser, E. J., 2003. The diurnal cycle of rainfall and convective intensity according to three years of TRMM measurements. Journal of Climate 16 (10), 1456-1475.

Nicholson, S. E., McCollum, J., Nelin, E., coauthors, 2003. Validation of TRMM and other rainfall estimates with a high-density gauge dataset for West Africa. Part II: Validation of TRMM rainfall. Journal of Applied Meteorology 42, 1355-1368. 
Pathan, J. M., 1994. Diurnal variation of southwest monsoon rainfall at Indian stations. Advances in Atmospheric Sciences 11 (1), 111-120.

Prat, O. P., Nelson, B. R., 2014. Characteristics of annual, seasonal, and diurnal precipitation in the Southeastern United States derived from long-term remotely sensed data. Atmospheric Research $144,4-20$.

Qian, J.-H., Robertson, A. W., Moron, V., 2013. Diurnal cycle in different weather regimes and rainfall variability over borneo associated with ENSO. Journal of Climate 26, 1772-1790.

Rahman, S. H., Sengupta, D., Ravichandran, M., 2009. Variability of Indian summer monsoon rainfall in daily data from gauge and satellite. Journal of Geophysical Research 114, D17117.

Rodger, C. J., Brundell, J. B., Holzworth, R., Lay, E. H., Crosby, N. B., Huang, T.-Y., Rycroft, M. J., 2009. Growing detection efficiency of the World Wide Lightning Location Network. In: Crosby, N. B., Huang, T.-Y., Rycroft, M. J. (Eds.), Coupling of Thunderstorms and Lightning Discharges to Near-Earth Space. American Institute of Physics, pp. 15-20.

Ruane, A. C., Roads, J. O., 2007. 6-hour to 1-year variance of five global precipitation sets. Earth Interactions $11,1-29$.

Rudlosky, S. D., Shea, D. T., 2013. Evaluating WWLLN performance relative to TRMM/LIS. Geophysical Research Letters 40, 1-5.

Sahany, S., Venugopal, V., Nanjundiah, R. S., 2010. Diurnal-scale signatures of monsoon rainfall over the Indian region from TRMM satellite observations. Journal of Geophysical Research 115 (D2), 1-14.

Sen Roy, S., Balling, Jr., R. C., 2013. Diurnal variations in summertime lightning activity in Tropical Asia. International Journal of Climatology 33, 1830-1836.

Shin, D. B., Kim, J. H., Park, H. J., 2011. Agreement between monthly precipitation estimates from TRMM satellite, NCEP reanalysis, and merged gauge-satellite analysis. Journal of Geophysical Research 116, D16105.

Shin, K., North, G. R., Ahn, Y. S., Arkin, P. A., 1990. Time scales and variability of area-averaged tropical oceanic rainfall. Monthly Weather Review 118 (7), 1507-1516.

Simpson, J., Kummerow, C., Tao, W. K., Adler, R. F., 1996. On the tropical rainfall measuring mission (TRMM). Meteorology and Atmospheric Physics 60 (1), 19-36.

Sorooshian, S., Gao, S., Hsu, K., Maddox, R. A., Hong, Y., Gupta, H., Imam, H. B., 2002. Diurnal variability of tropical rainfall retrieved from combined GOES and TRMM satellite information. Journal of Climate 15, 983-1001.

Teo, C.-K., Koh, T.-Y., Lo, J. C.-F., Bhatt, B. C., 2011. Principal component analysis of observed and modeled diurnal rainfall in the maritime continent. Journal of Climate 24, 4662-4675. 
Virts, K. S., Wallace, J. M., Hutchins, M. L., Holzworth, R. H., 2013a. Diurnal lightning variability over the maritime continent: Impact of low-level winds, cloudiness, and the MJO. Journal of the Atmospheric Sciences 70, 3128-3146.

Virts, K. S., Wallace, J. M., Hutchins, M. L., Holzworth, R. H., 2013b. Highlights of a new groundbased, hourly global lightning climatology. Bulletin of the American Meteorological Society 94, 1381-1391.

Wallace, J. M., 1975. Diurnal variations in precipitation and thunderstorm frequency over the conterminous United States. Monthly Weather Review 103 (5), 406-419.

Wu, P., Yamanaka, M., Matsumoto, J., 2008. The formation of nocturnal rainfall offshore from convection over western Kalimantan (Borneo) Island. Journal of the Meteorological Society of Japan 86A, 187-203.

Yang, G. Y., Slingo, J., 2001. The diurnal cycle in the tropics. Monthly Weather Review 129 (4), 784-801.

Yang, S., Smith, E. A., 2008. Convective-stratiform precipitation variability at seasonal scale from 8 years of TRMM observations: Implications for multiple modes of diurnal variability. Journal of Climate 21, 4087-4114.

Zipser, E. J., 1994. Deep cumulonimbus cloud systems in the tropics with and without lightning. Monthly Weather Review 122, 1837-1851.

Zuidema, P., 2003. Convective clouds over the Bay of Bengal. Monthly Weather Review 131, 780-798. 


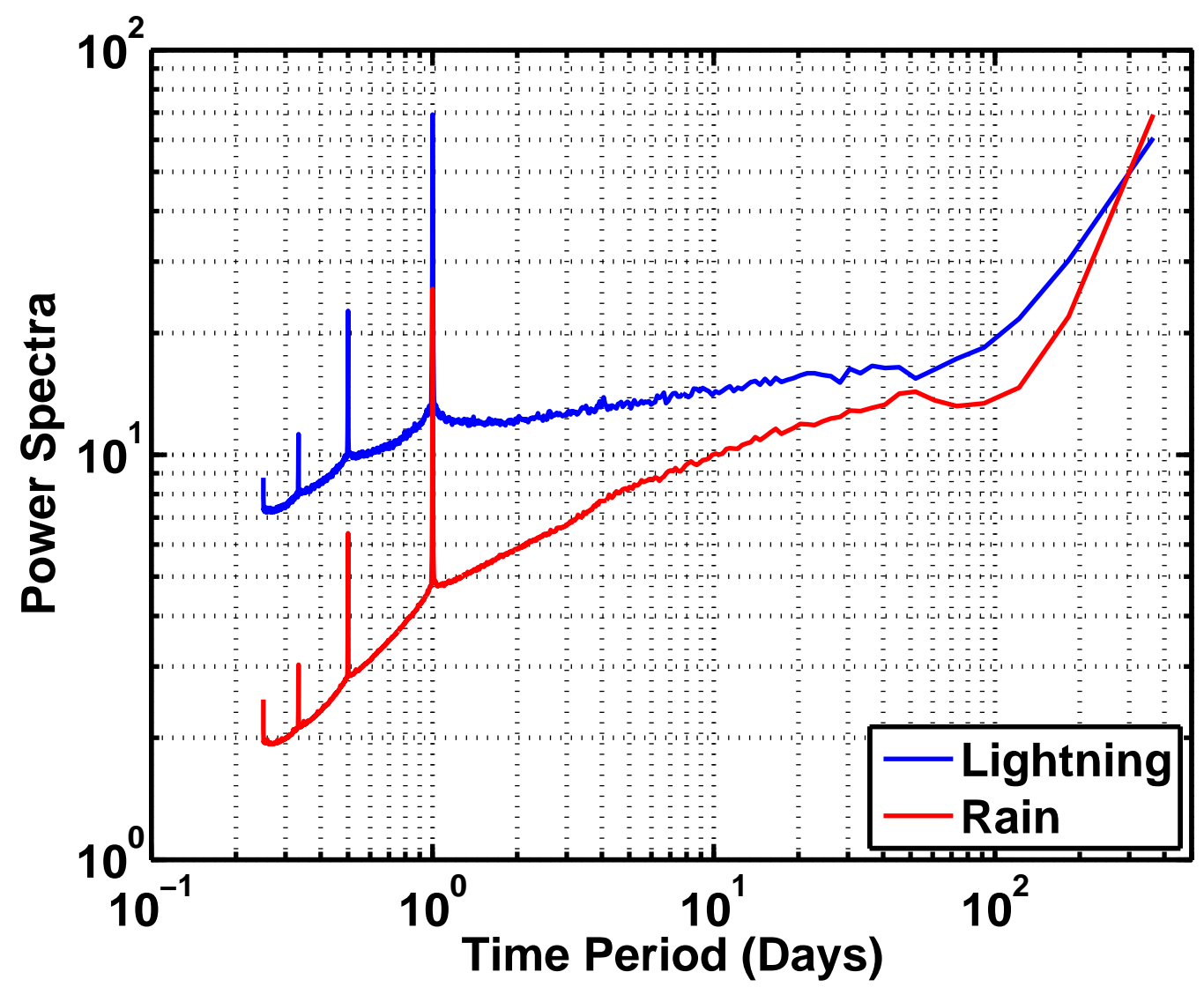

Figure 1: Climatological power spectrum of lightning (blue; 2008-2011; WWLLN) and rain (red; 1998-2012; TRMM 3B42V7) based on 0.25-degree, 3-hourly observations. The climatology shown is the spatial average of the spectrum estimated at each grid point. 
(a)

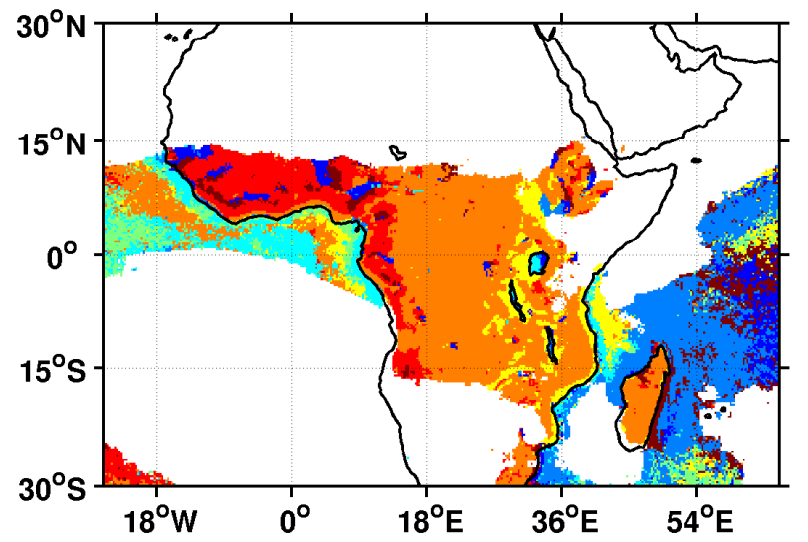

(c)

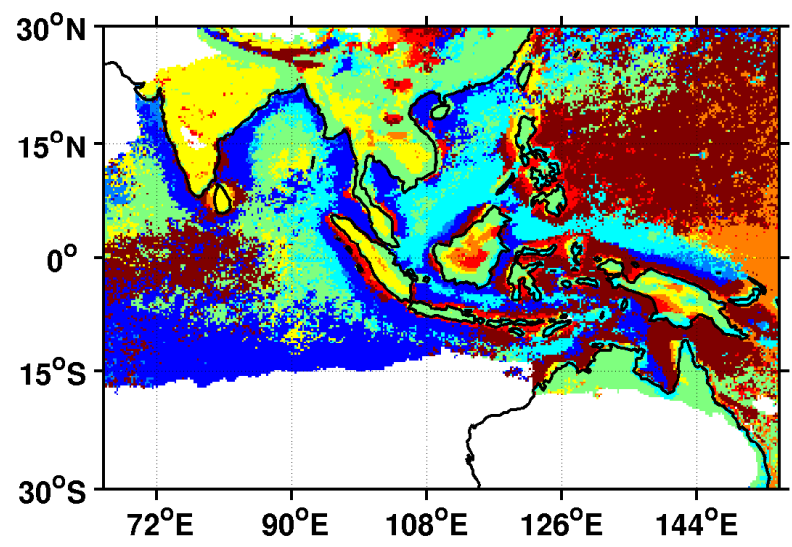

(e)

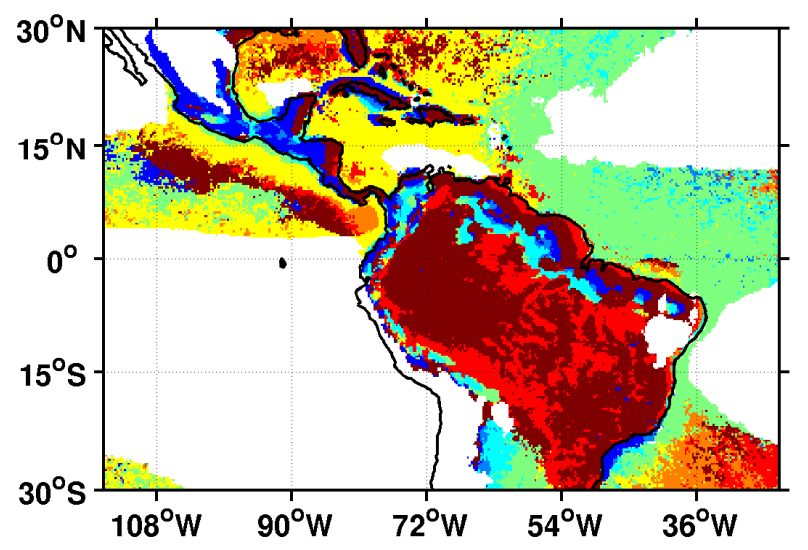

(b)

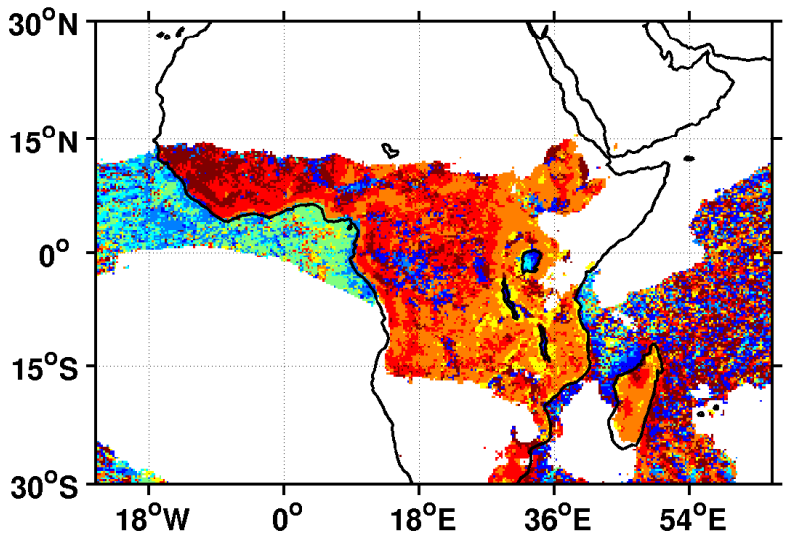

(d)

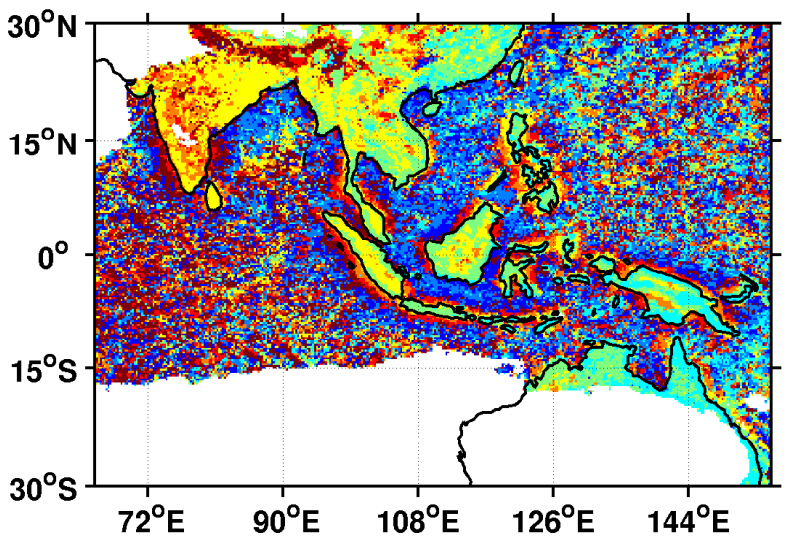

(f)
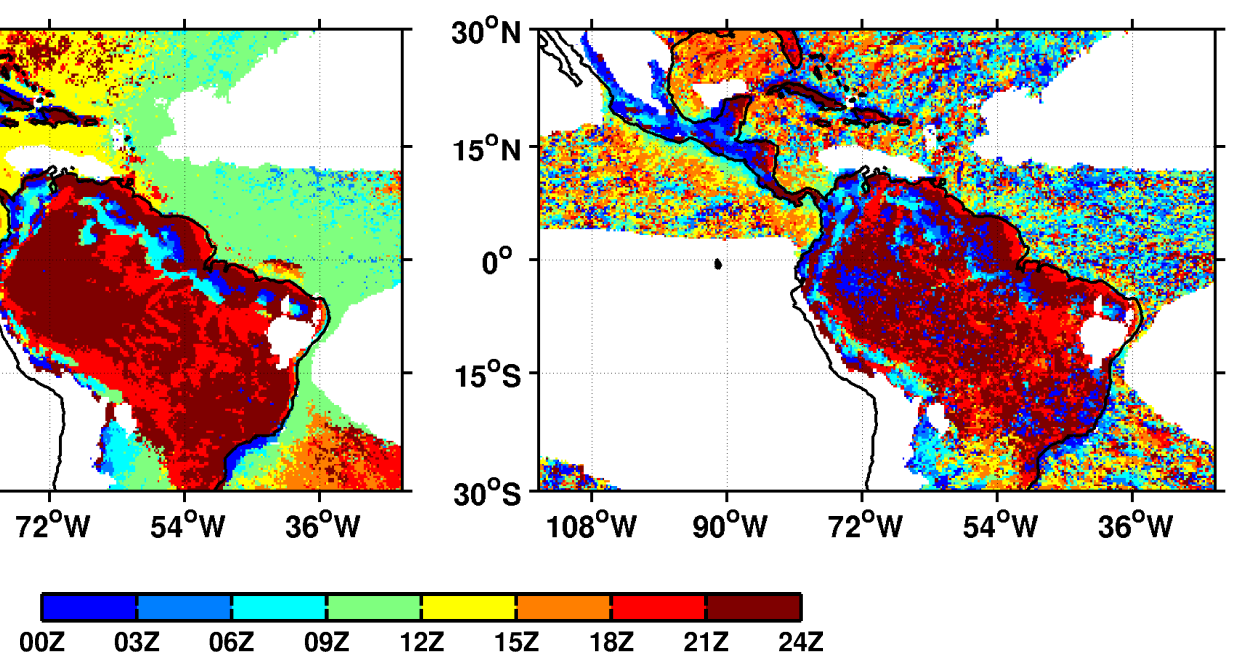

Figure 2: Comparison of the phase of the diurnal maximum (in UTC) of tropical rain (left column) and lightning (right column). The white area in the panels corresponds to regions which receive an annual mean rain less than $2 \mathrm{~mm} / \mathrm{d}$. 


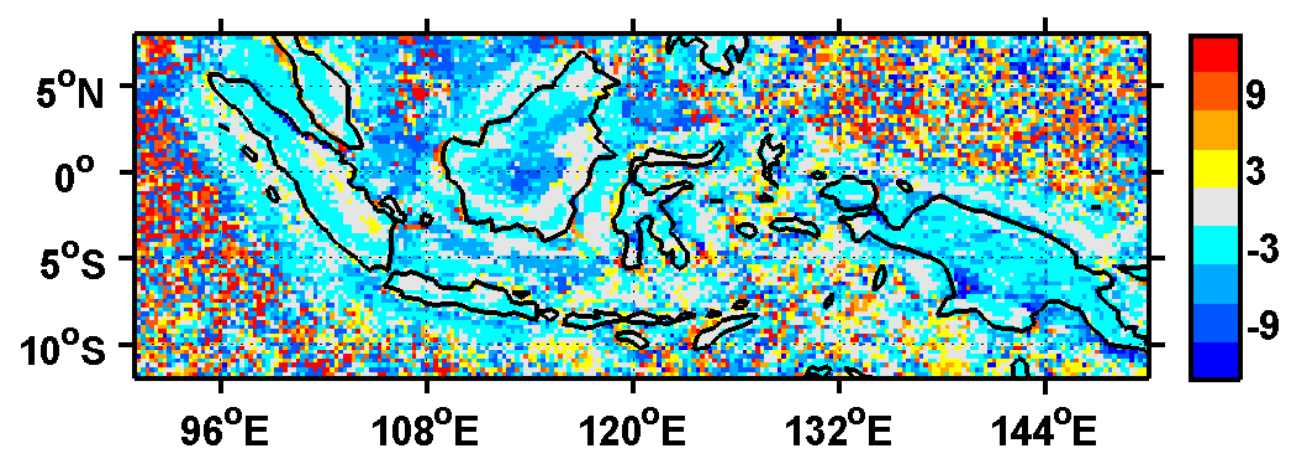

Figure 3: Difference (lightning - rain) of the phase of the diurnal maximum (in hours) over the Indonesian islands. Negative (Positive) values indicate that the lightning maximum leads (lags) that of rain. 

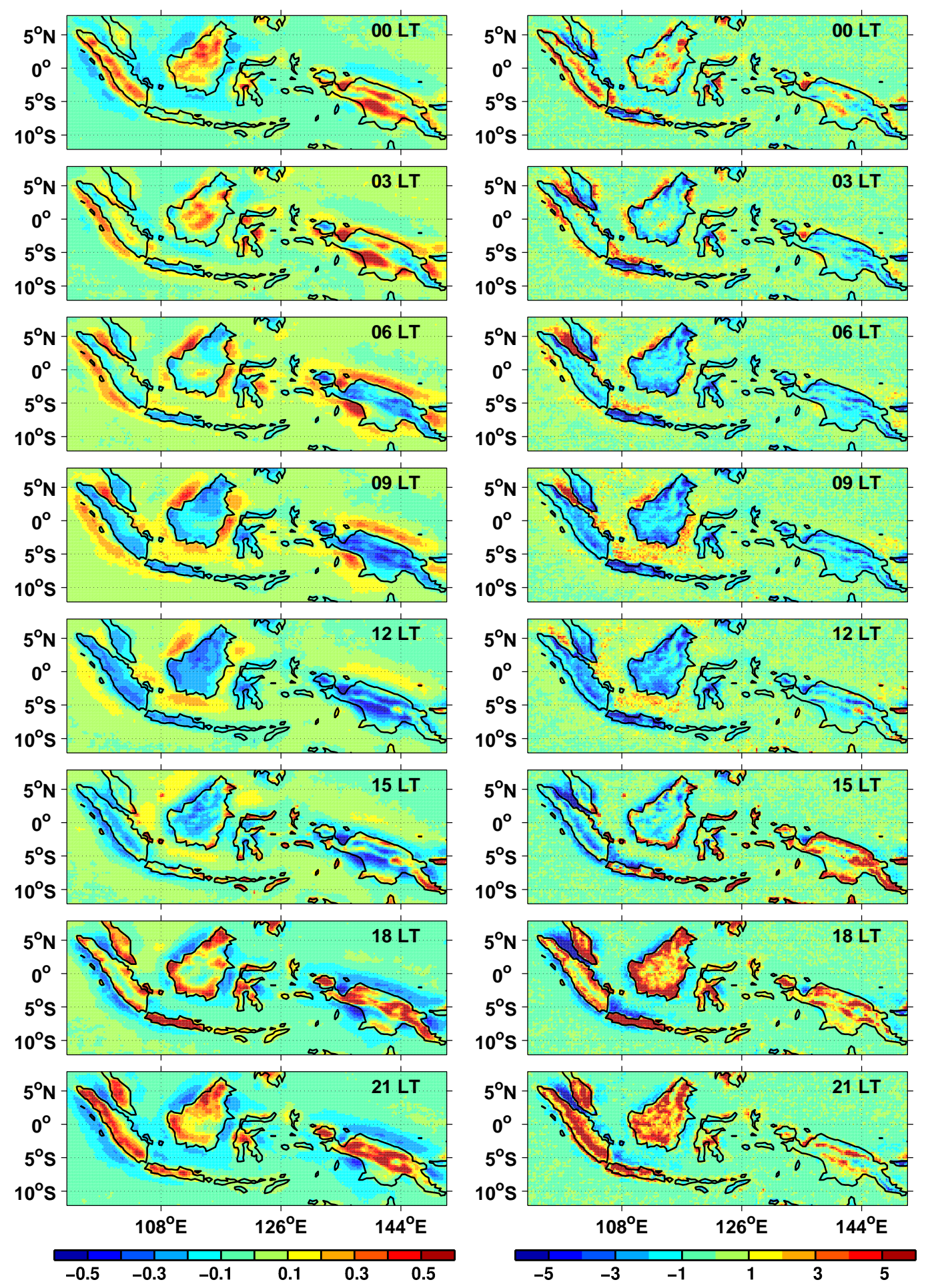

Figure 4: Climatology of diurnal anomalies of (left column) rainfall ( $\mathrm{mm} / \mathrm{h})$ from TRMM (3B42V7; 1998-2012) and (right column) lightning (strokes $\mathrm{km}^{-2} \mathrm{yr}^{-1}$ ) from WWLLN (2008-2011) over the Indonesian islands, for each of the eight octets. The local times shown are for $110^{\circ} \mathrm{E}$. 


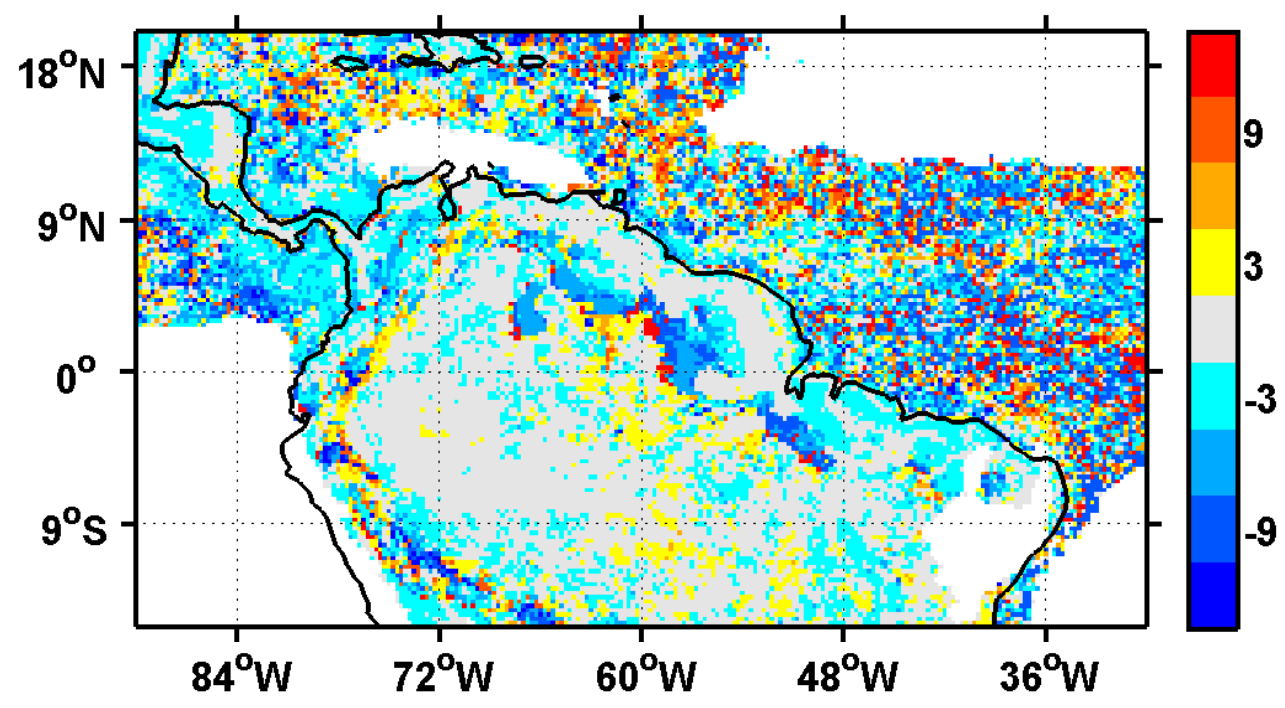

Figure 5: As in Fig. 3, but over South America. The white area in the panel corresponds to regions which receive an annual mean rain less than $2 \mathrm{~mm} / \mathrm{d}$. 

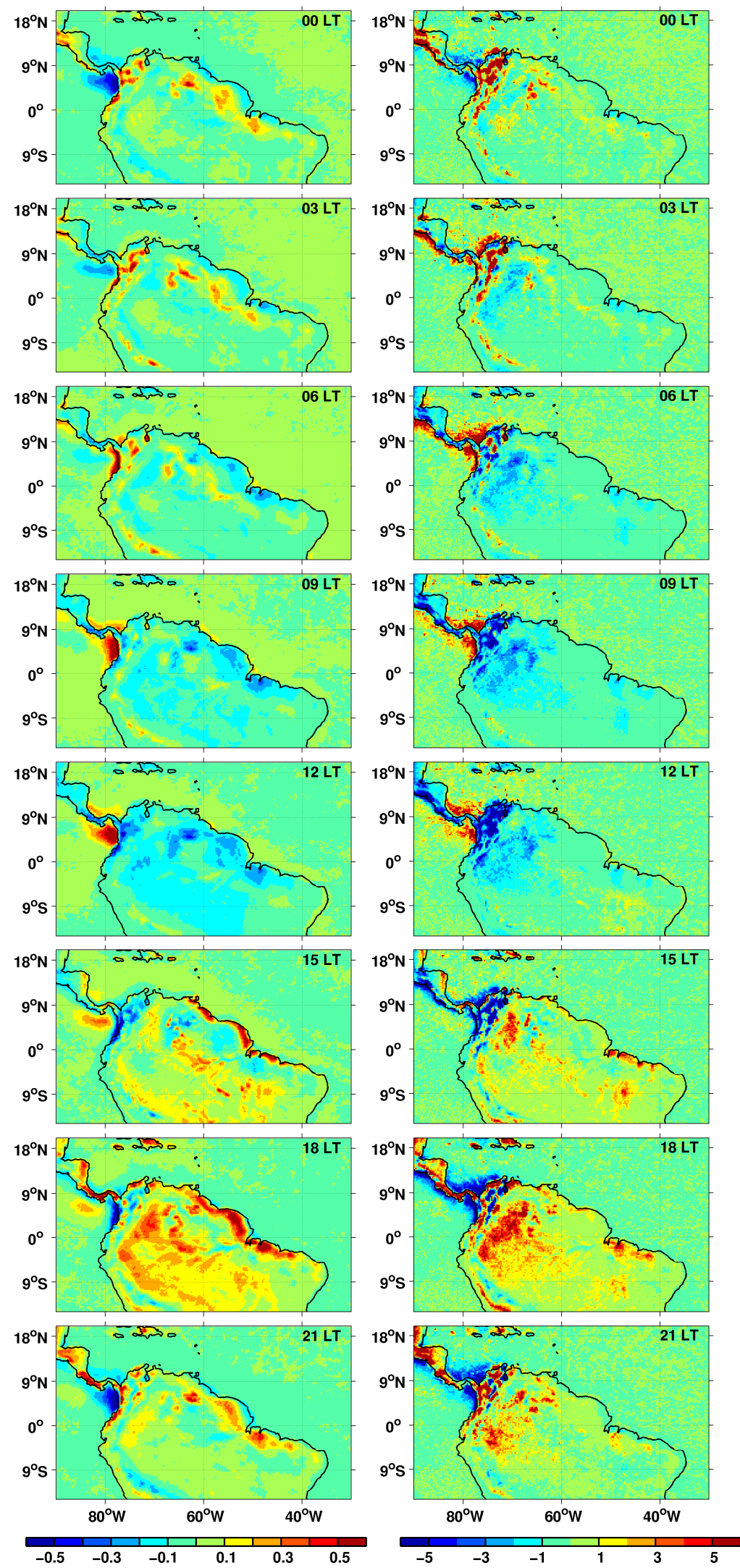

Figure 6: As in Fig. 4, but over South America. The local times shown are for 70W. 